\title{
Comparison of FE analysis and experimentally obtained data for the identification of residual stresses in welded high-strength steel
}

\author{
Milan Vaško ${ }^{1, *}$, Vladislav Baniari ${ }^{1}$, Marián Handrik ${ }^{1}$, Alan Vaško $^{2}$, Lenka Jakubovičová ${ }^{1}$, \\ Peter Kopas ${ }^{1}$ \\ ${ }^{1}$ University of Žilina, Faculty of Mechanical Engineering, Department of Applied Mechanics, \\ Univerzitná 8215/1, Žilina, Slovak Republic \\ ${ }^{2}$ University of Žilina, Faculty of Mechanical Engineering, Department of Materials Engineering, \\ Univerzitná 8215/1, Žilina, Slovak Republic
}

\begin{abstract}
The main idea of this paper is to compare the results of FE analysis and data obtained by experiment for identification of residual stresses in welded high-strength steels. The DOMEX steels welded by two technologies are compared - steel welded with laser beam and steel welded by electric arc. Residual stresses at the surface and just below the surface were evaluated using X-rays at predefined points. These data were subsequently processed in MATLAB and evaluated. FE analyzes were performed in software SYSWELD and ADINA.
\end{abstract}

Keywords: residual stress, high-strength steel, DOMEX 700MC, welding, weld joint, MATLAB, SysWeld, ADINA, FE analysis

\section{Introduction}

Steel is the most commonly used material in the engineering industry. Steel can be obtained at relatively low economic costs and the extent of its use is enormous. High-strength steels are a product of modern thermo-mechanical processing. It offer many positive properties, such as high tensile strength, finer internal structure, a low carbon content for improved weldability and controlled internal purity. The chemical composition of the material depends on its thickness and purpose. The carbon content ranges from $0.05 \%$ to $0.25 \%$ depending on the weldability and the formability. Smaller material thickness can be used for practical application due to these properties.

High-strength steel DOMEX 700 MC (resp. STRENX) will be used for the purpose of experimental measurements. This is low carbon steel, which greatly improves the welding conditions. Steel do not need heat treatment before or after the welding process. It is not predisposed to excessive hardening, is resistant to cold fracture and suitable for all types of welding. Welding of this steel is different compared to the welding of conventional steels.

\footnotetext{
* Corresponding author: milan.vasko@fstroj.uniza.sk

Reviewers: Marcin Kubiak, Alžbeta Sapietová
} 
Two methods of welding specimens (laser and MAG welding method) were used for the purpose of residual stresses analysis. Laser welding was performed using solid-state fiber laser YLS-5000 from IPG Laser Company. MAG welding was carried out using the OTC DAIHEN welding robot and welding electric power supply. OK AristoRod 69 non-plated coppered wire was used as an additive material [1].

\section{Residual stresses}

Residual stress can be defined as the stress inside the material after removal of all load forces. If the material is compressed, we are talking about pressure residual stresses that characterize negative values. If the material is pulled, it is a tensile residual stress with positive values. Normal residual stresses are acting perpendicularly to the surface and the shear residual stresses act in the plane of the material surface [2,3].

Residual stresses arise after plastic deformations. It is caused by mechanical loading, thermal loading and phase changes. If mechanical and/or thermal loads are applied during product preparation, it is possible to create residual stresses in the material according to certain requirements. This can ultimately have a positive effect on the properties.

Knowledge of residual stresses values is also important for correct determination of the actual load on structure components [4]. The pressure residual stresses created on the surface of the component are in principle beneficial. They increase fatigue limit and fatigue life, slow down the formation of fractures resulting from the action of stress and corrosion. Tensile residual stresses create exactly the opposite effects in the material.

The location and size of the residual stresses need to be known to determine how they are expanded in the material. Summarizing the following three stress types we obtain the total residual stress [1]:

- Microstresses - stresses arise inside the material between the grains and act at short distances along the grain boundaries in single-phase and multi-phase materials. In the case of single-phase materials, this causes the anisotropic behavior of individual grains. In the case of multi-phase materials it is due to the different phases.

- Macrostresses - grow inside the material between the grains and act on long distances.

- Stresses without specific denotation - they accumulate inside the material by the influence of crystal imperfections inside the grains.

\section{X-ray method for analyzing the residual stress}

The X-ray device works on a quantitative principle and has the appropriate resolution in relation to the measured area. The device performs a measurement on the surface or just below the surface and based on the measured data, it evaluates the residual stresses in measured points. The stress is determined by the measurement of the distance between crystallographic planes. The non-destructive acquisition of values is the advantage of this measuring instrument [2].

\subsection{Residual stresses measured on laser welded specimens}

Residual stresses have arisen in the vicinity of the welding area after laser welding. The laser welding causes thermal changes in thermo-mechanically modified material and its concentrated energy source with low heat dissipation reduces the original stresses in the material $[5,6]$. The test specimen of DOMEX 700MC high-strength steel welded in both ways is shown in Fig. 1 . The dimensions of the test specimens were $200 \times 10 \times 10 \mathrm{~mm}$. 
Residual stress values were measured on individual sample areas and converted using MATLAB software $[7,8,9]$. Total decrease of pressure stresses was measured on the sidewall of the specimen ( $y z$ plane). Center of the measurement area shows higher stress values. The stress decreases towards the edge of the surface due to the solidification of the welding bath (Fig. 2). The stress in welding again decreased when measured on a welded area ( $x z$ plane). The center of the measured area retained higher pressure stresses that declined continuously towards the edges. This was again caused by solidification of the welding bath and crystallization of the grains (Fig. 3).

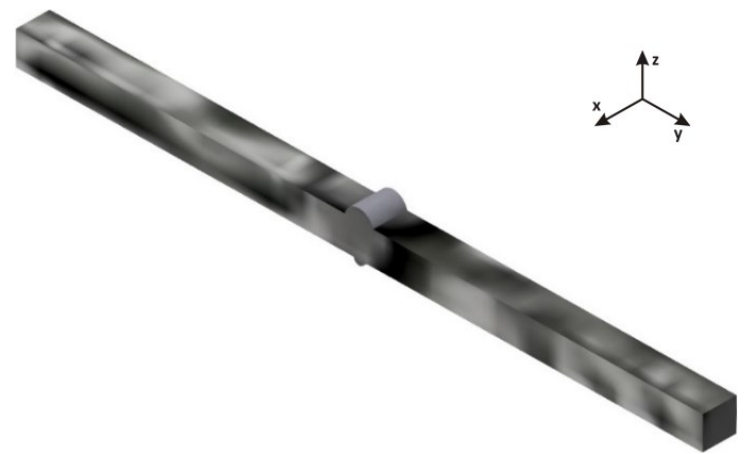

Fig. 1. Welded specimen of DOMEX 700MC high-strength steel
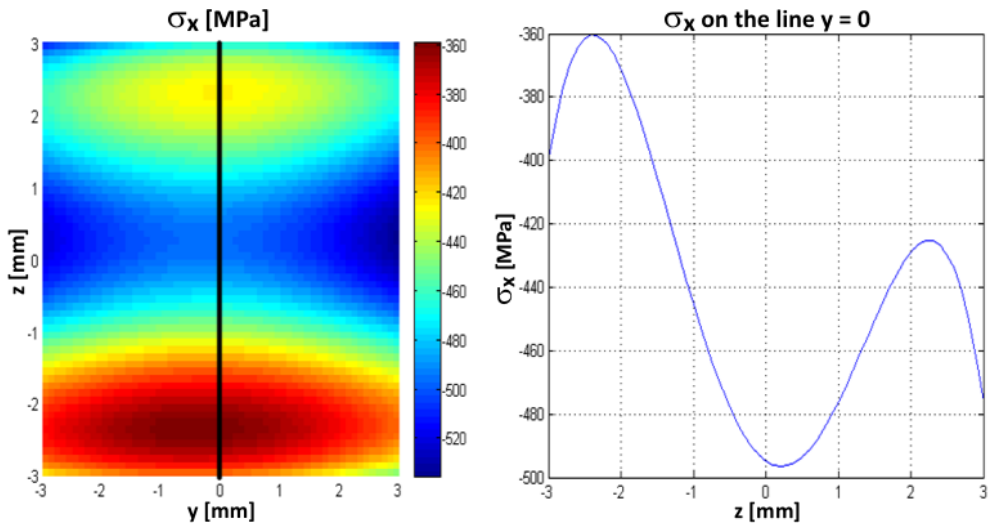

Fig. 2. Normal stress on the sidewall of the welded specimen
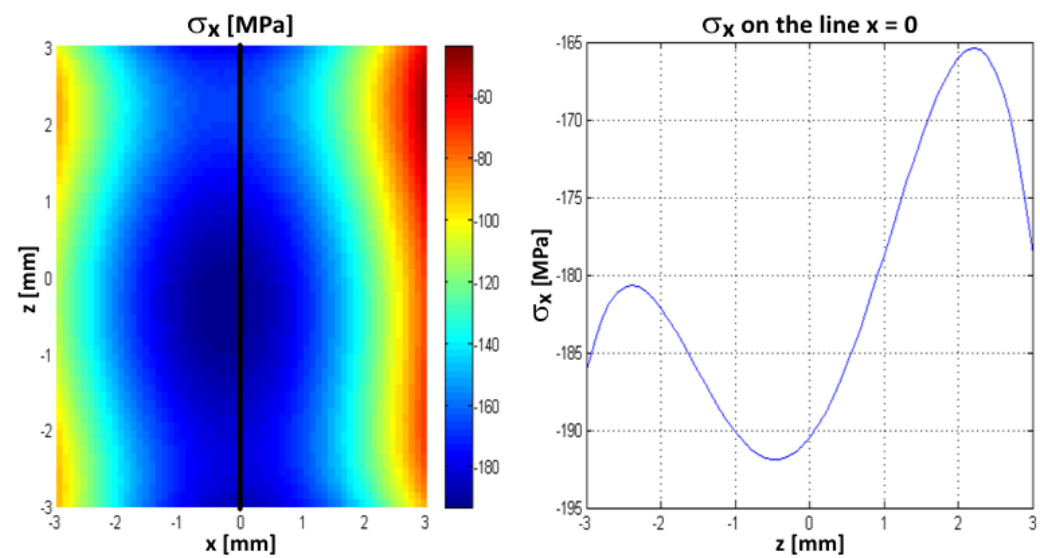

Fig. 3. Normal stress on the area passed through the weld 
The normal stress value of the base material has decreased by about $25 \%$ on the sidewall. The residual stresses on the surface of the weld decreased by more than $80 \%$. The significant decrease also contributed to the fact that it is a plane perpendicular to the original direction of rolling of the material.

\subsection{Residual stresses measured on arc welded specimens}

Different residual stresses in comparison to the base material have arisen in the vicinity of the weld joint for both types of welding. The authors anticipated an increased influence of arc welding on the stress change before the measurement, therefore a larger sample area than in laser welding was evaluated $[1,6]$.

Pressure stresses in the $y$-axis direction increased in the vicinity of the weld when measured on the sidewall of the specimen ( $y z$ plane). This was caused by the additional material that reacted with the base material and pushed away the material into the vicinity of the welding bath. The normal stresses rise to the higher values from the edge of the weld in the $x$ direction as well as at the normal stresses in the $y$ direction. Change of compressive stresses to tensile stresses occurred at the top of the weld. This was probably due to solidification or crystallization of the weld metal (Fig. 4).
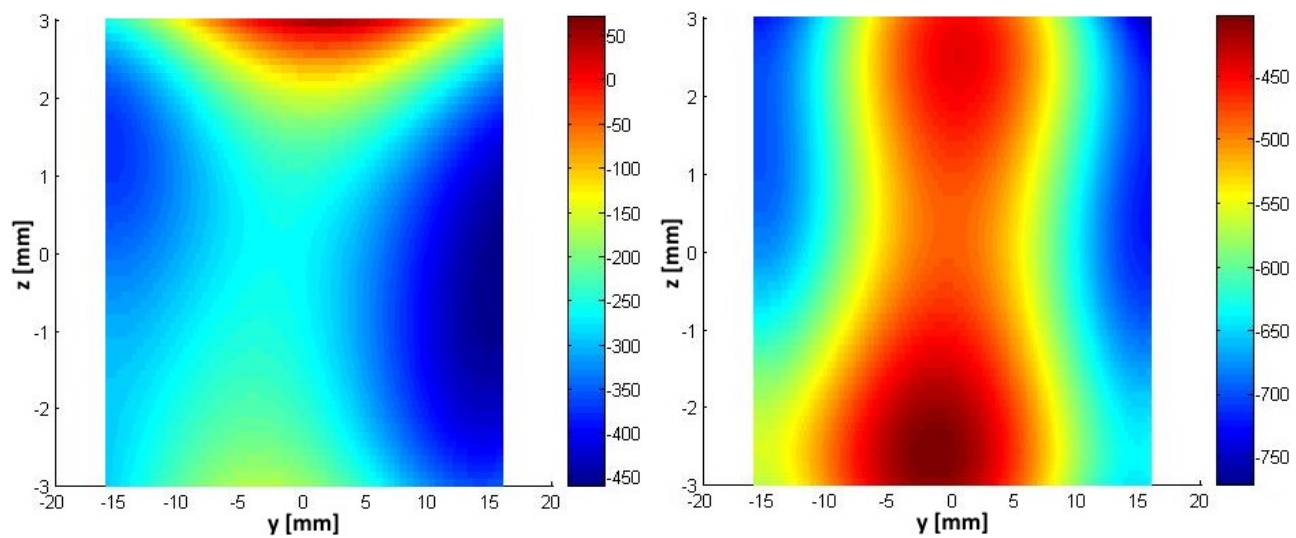

Fig. 4. Normal stresses in $x$-axis direction (left) and in $y$-axis direction (right) on the sidewall
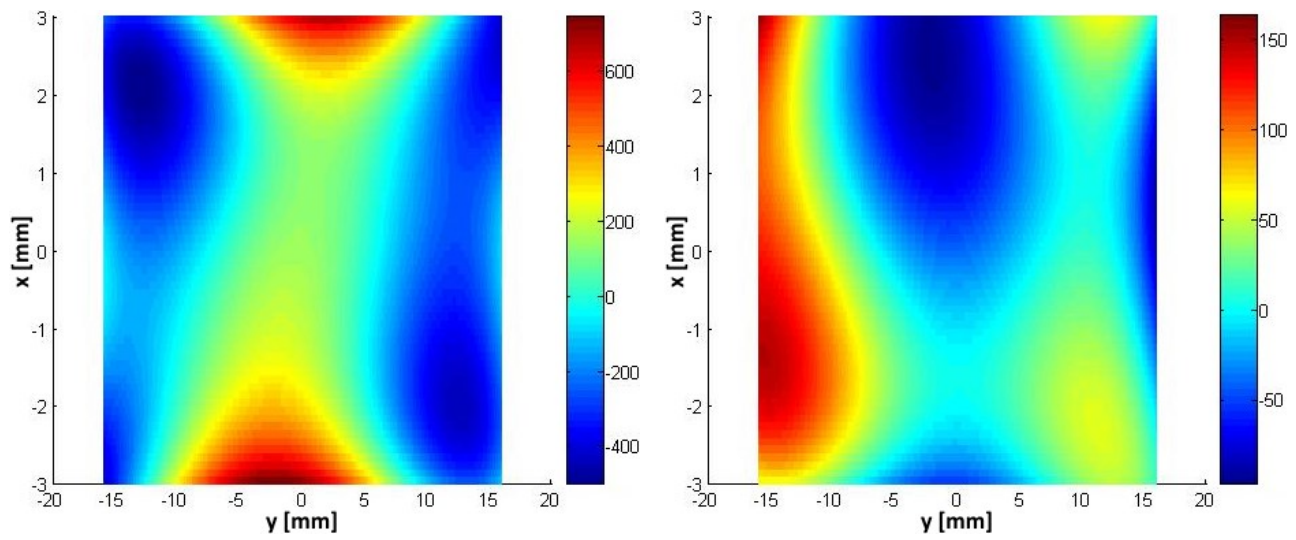

Fig. 5. Normal stresses in $x$-axis direction (left) and in $y$-axis direction (right) on the surface 
The normal stress in the $y$-direction increased from the welding point on both sides of the sample when measured on the upper surface of the welded specimen ( $x y$ plane). The weld joint has a low pressure normal tension. The tension stresses at the edges of the welding joint are probably locally generated due to crystal stiffening and phase change. The normal stress in the $x$-direction has grown just at the weld joint, which is caused by the formation of the welding bath at the welding direction and the gradual stiffening and tightening up. The vicinity of the weld shows a decrease in the stress to negative values. This is again caused by the additional material (Fig. 5).

\section{Analysis of the weld microstructure}

The microstructure of the material at the weld joint and in the heat-affected area should be known for the creation of real FE models for FE analysis in SysWeld and ADINA software $[10,11]$. The microstructure analysis was made on welded specimens of the DOMEX 700MC material at the Department of Materials Engineering, University of Žilina.

Thermo-mechanical made DOMEX steel is characterized by fine-grained ferrite, specifically with elongated grains in the rolling direction. Excluded $\mathrm{Fe}_{3} \mathrm{C}$ carbide appears somewhere in ferrite. Laser is a technology that significantly less heat affects the area of the welding vicinity than arc welding. The microstructure of the weld joint for laser welded specimens is shown in Fig. 6. The structure of the heat-affected zone and the weld joint is shown in Fig. 7. The change of the grains size is shown in the figure. Ferrite was converted to acicular ferrite with a partial existence of impurities in the weld metal microstructure.

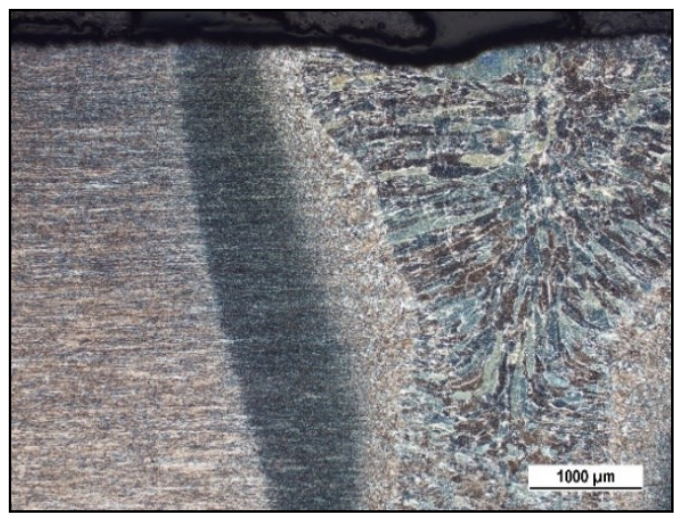

Fig. 6. Laser weld joint of DOMEX 700MC material
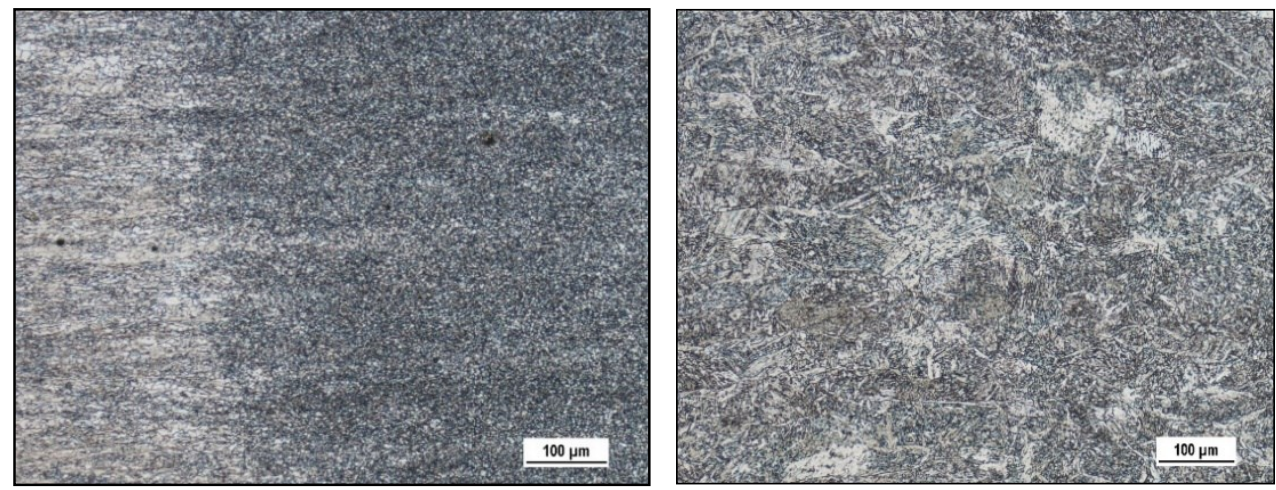

Fig. 7. Heat-affected zone (left) and weld metal (right) after laser welding 
The microstructure of the arc welded specimens demonstrates the presence of a larger heat-affected area along with a greater number of inclusions. This is due to greater heat dissipation in the welding vicinity during the welding process and the additive material. The microstructure of the weld joint for arc welded specimens is shown in Fig. 8. The structure of the heat-affected zone and the weld joint is shown in Fig. 9.

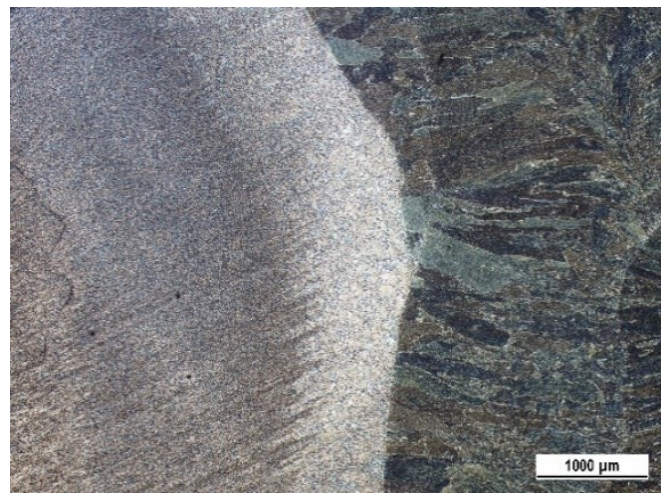

Fig. 8. Arc weld joint of DOMEX 700MC material
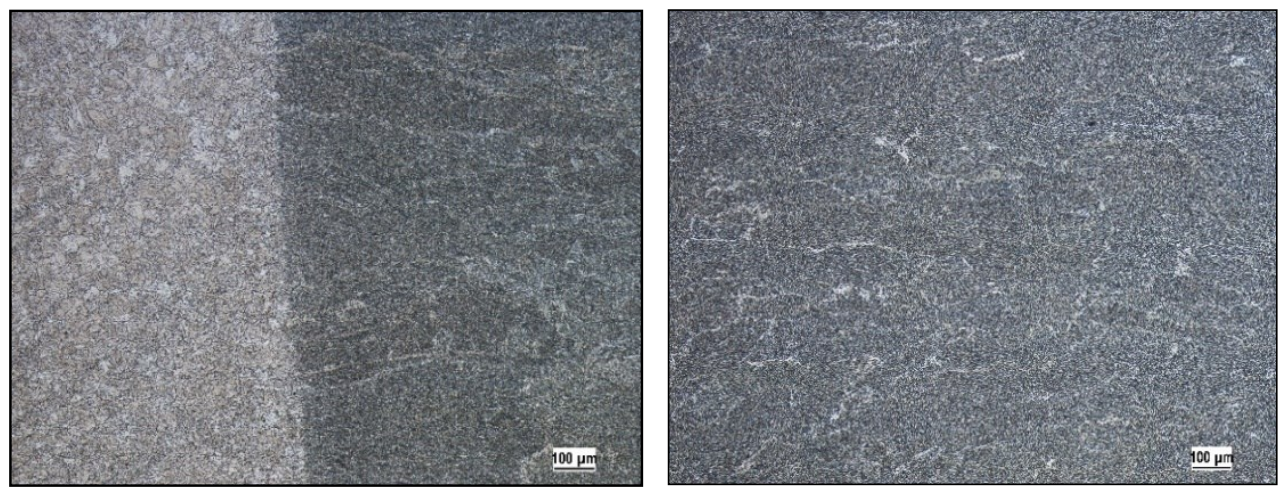

Fig. 9. Heat-affected zone (left) and weld metal (right) after arc welding

\section{Residual stress analyses using FE software}

Virtual models for analysis in ADINA and SysWeld software were created based on real material samples (dimensions, material properties, etc.) and experimentally detected microstructure of the material at weld joint and in the vicinity of the weld joint $[12,13,14]$. The laser welding model has been selected for these analyzes because the philosophy of the created residual stresses is similar to the arc-welded model.

\subsection{Analysis using SysWeld software}

SysWeld software can simulate the welding process and it eliminate the need for produce prototypes of welded structures and reducing the time and cost of production. SysWeld helps to control and optimize the entire welding process. It uses mathematical algorithms that apply the laws of physics that affect the entire welding process in reality. SysWeld provides analysis results from all areas of the analyzed sample welding process (phase 
transformations, heat-affected zones, latent heat, grain size change, plasticity due to transformation, hardness, tensile strength, residual stress, etc.) [15].

SysWeld works most precisely with hexagonal elements when calculating weld joints. The model was created based on the above data that contained two basic materials, the weld joint, the heat-affected zone and the weld root. Material databases are used in the analysis to be assigned to the relevant parts of the welding model. Subsequently, the welding trajectory is formed and the basic welding data are inserted (angle of laser beam impact on the base material surface, welding speed, starting point and end of welding, etc.).

The results of the normal stresses with small differences correspond to the results mentioned above. Tensile stresses in the $x$-direction are located in the weld core and pass smoothly into compressive stresses towards the edges of bonded plates. Normal stresses in the $y$-axis direction show a similar progress. Tensile stresses are again located in the core of the weld. These stresses act up to 4/5 of the welded plate width. Tensile normal stresses in the $x$-direction are also concentrated in the vicinity of the weld joint. The detailed view of normal residual stresses in the $x$-axis direction is shown in Fig. 10.

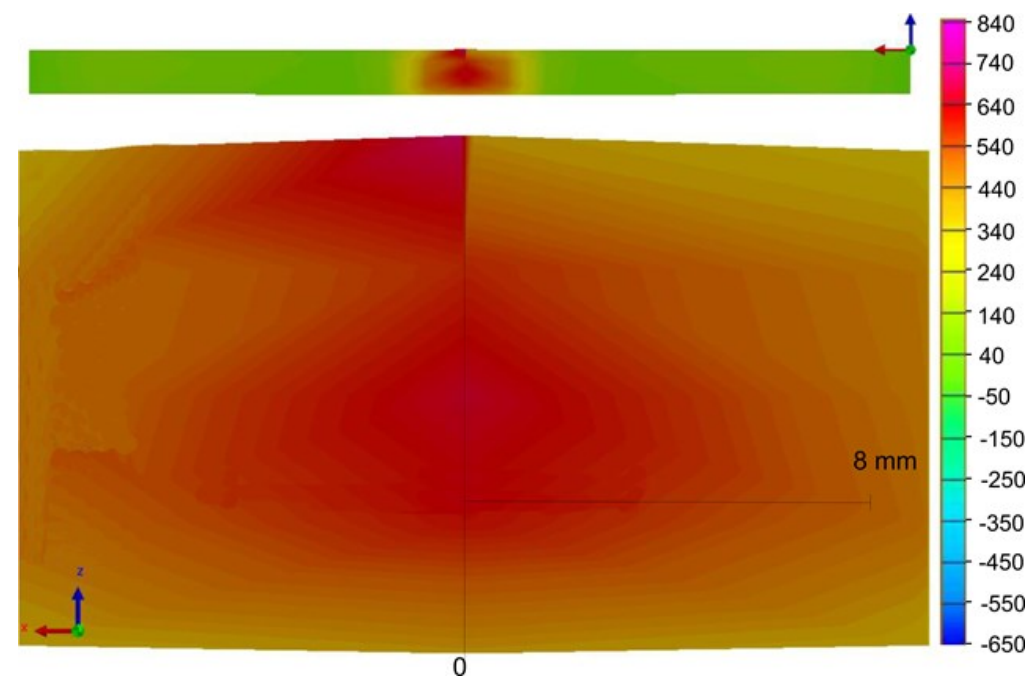

Fig. 10. The detailed view of normal residual stresses in the $x$-axis direction (SysWeld)

\subsection{Analysis using ADINA software}

Residual stresses in relative terms were evaluated in the program ADINA. Exact numerical values have not been used, although real values of welding have entered into the boundary conditions. This calculation was used as a verification tool for comparing the results of the SysWeld software with the measured X-ray device values.

The model was mainly designed to verify the possibility of modeling heat transfer between the elements representing the laser beam and the base material by radiation (modeling of the moving boundary condition - the moving heat source) [10, 16-17]. Results from the ADINA software disregarded phase changes as it is known in terms of materials engineering. The algorithm in the thermal part of the ADINA software is able to work with temperature changes (i.e. heating and cooling) and to evaluate the stresses as positive and negative. The numerical values in this analysis are not significant - the distribution of normal stresses in the direction of the corresponding axis is important [11, 18-20].

Negative (pressure) stresses were created after cooling on the surface of two welded plates. The pressure stresses remain at the welding edges under ideal conditions of uniform heating and cooling without introducing errors in the welding process. Stresses in the core of 
the model have risen to positive values. The detailed view of normal residual stresses in the $x$-axis direction is shown in Fig. 11 .

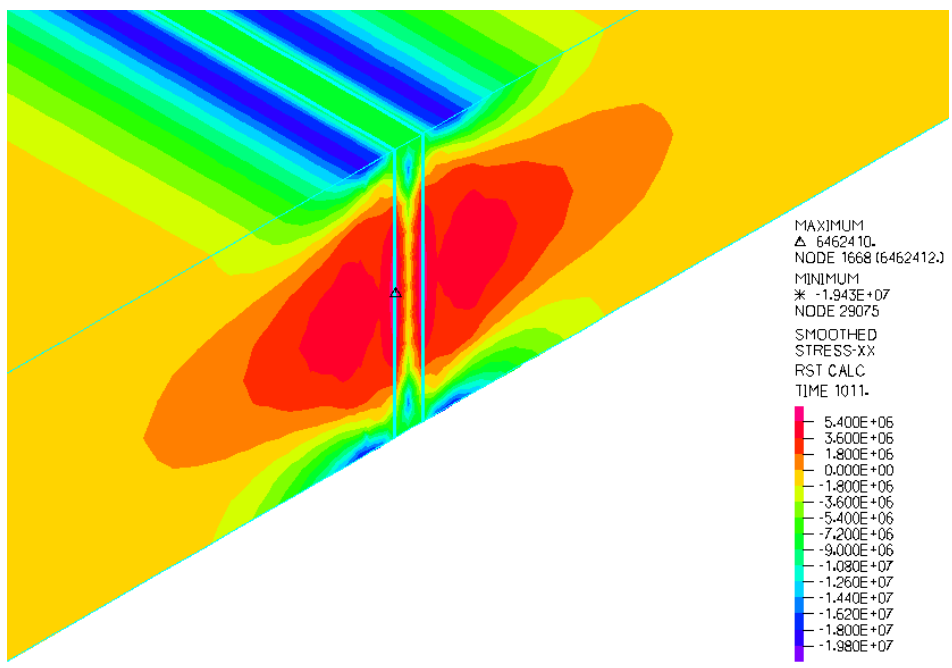

Fig. 11. The detailed view of normal residual stresses in the $x$-axis direction (ADINA)

\section{Conclusions}

Laser welding with its low-dispersion heat-shifting beam has ensured smooth transitions of normal stresses. Arc welding causes that concentrated heat and additional material significantly affects the surrounding structure of the joined materials and cause significant change phases. The values of residual stresses are lower than in laser welding, but the Domex $700 \mathrm{MC}$ material has high residual stresses from the thermo-mechanical process. Arc welding thus significantly affected a larger area in a negative direction and removed pre-defined stresses from the base material.

The results of the X-ray device do not show the same polarity of the stresses in the specimen core. It is assumed that these measured data were negative (from the sidewall) due to the rotation of the structure, respectively due to cutting by the band saw. The mathematical model does not consider rotation of the structure in the opposite direction (e.g. due to machining). Another important factor is that DOMEX 700MC steel has rotated crystallographic planes in the rolling direction for the thermo-mechanical machining of the steel. It is also not easy to apply this feature to the model of the analyzed specimen in the FE software ADINA. It could be solved by the assumption of prestress, but it cannot be guaranteed that the welded real steel plate has a grain structure rotated in the same direction as the modeled specimen.

This work was supported by the Slovak Research and Development Agency under the contract No. APVV-14-0096 and work was supported by KEGA 037ŽU-4/2018 "Implementation of effective computational tools into modern information and communication technologies with the aim of increasing competencies of graduates of technical studies".

\section{References}

1. V. Baniari, Contribution to evaluation of fatigue damage of welded joints of DOMEX high-strength steels in order to improve their bearing capacity. [Dissertation thesis] (University of Žilina, 110 p., 2018) 
2. V. Baniari, M. Blatnická, M. Šajgalík, M. Vaško, M. Sága, Measurement and numerical analyses of residual stress distribution near weld joint. Procedia Engineering 192, 2227 (2017)

3. R. Halama, A. Markopoulos, F. Fojtik, M. Fusek, Z. Poruba, J. Famfulík, Effect of stress amplitude on uniaxial ratcheting of aluminum alloy 2124-T851. Materialwissenschaft und Werkstofftechnik 48 (8), 814-819 (2017)

4. J. Stancek, V. Bulej, Design of driving system for scissor lifting mechanism. Acad. J. of Manufacturing Eng. 13, 38-43 (2015)

5. M. Macko, K. Tyszczuk, G. Śmigielski, J. Flizikowski, A. Mroziński, Utility of an unitary-shredding method to evaluate the conditions and selection of constructional features during grinding. MATEC Web of Conerences 157 (05016), 1-7 (2018)

6. M. Sapieta, V. Dekýš, A. Sapietová, Thermal-stress analysis of beam loaded by 3 point bending. Procedia Engineering 136, 216-219 (2016)

7. MATLAB. [online] https://www.mathworks.com/products/matlab.html

8. P. Oršanský, B. Ftorek, P. Durčanský, Mathematical model of a closed hot air engine cycle using MATLAB Simulink. XIX. The Application of Experimental and Numerical Methods in Fluid Mechanics and Energetic 2014, AIP Conference Proceedings 1608, 173-176 (2014)

9. P. Pecháč, M. Sága, Memetic algorithm with normalized RBF ANN for approximation of objective function and sedondary $R B F A N N$ for error mapping. Procedia Engineering 177, 540-547 (2017)

10. K. J. Bathe, Finite Element Procedures. (Prentice Hall, New Jersey, 1982)

11. ADINA, Theory and Modelling Guide, Vol. III, CFD and FSI. [Help manual] (2017)

12. M. Bara, T. Kmita, J. Korzekwa, Microstructure and properties of composite coatings obtained on aluminium alloys. Archives of Metallurgy and Materials 61 (3), 1107-1112 (2016)

13. R. Grega, J. Krajňák, L. Žul'ová, G. Fedorko, V. Molnár, Failure analysis of driveshaft of truck body caused by vibrations. Engineering Failure Analysis 79, 208-215 (2017)

14. W. Piekarska, M. Kubiak, Z. Saternus, Numerical simulation of deformations in T-joint welded by the laser beam. Archives of Metallurgy and Materials 58 (4) 1391-1396 (2013)

15. ESI Group 2015 SysWeld Reference Manual [User Manual] (2015)

16. M. Dudziak, A. Kołodziej, G. Domek, K. Talaśka, Multi-angularity - identification of parameters and compatibility conditions of the axisymmetric connection with form deviations. Procedia Engineering 177, 431-438 (2017)

17. P. Krawiec, Numerical Analysis of Geometrical Characteristics of Machine Elements Obtained Through CMM Scanning. Progress in Industrial Mathematics at ECMI 2008, Mathematics in Industry 15, Springer, Berlin, Heidelberg, 933-938 (2010)

18. B. Leitner, The procedure of fatigue damage estimation for mechanical structures under service loading. Transport Means 2014, $54-58$ (2014)

19. E. Kalentev, Š. Václav, P. Božek, A. I. Korshunov, V. Tarasov, Numerical analysis of the stress-strain state of a rope strand with linear contact under tension and torsion loading conditions. Advances in Science and Technology Research Journal 11 (2), 231239 (2017)

20. J. Zapoměl, V. Dekýšs, P. Ferfecki, A. Sapietová, M. Sága, M. Žmindák, Identification of material damping of a carbon composite bar and study of its effect on attenuation of its transient lateral vibrations. Int. Journal of Applied Mechanics 7 (6), (2015) 